\title{
Do Patient Positioning and Portal Placement for Arthroscopic Subtalar Arthrodesis Matter?
}

\author{
Alan G. Shamrock, ${ }^{\star \dagger}$ MD, Annunziato Amendola, ${ }^{\ddagger} \mathrm{MD}$, Natalie A. Glass, ${ }^{\dagger} \mathrm{PhD}$, \\ Keith H. Shamrock, ${ }^{\S}$ BS, Christopher C. Cychosz, ${ }^{\dagger}$ MD, Christopher N. Carender, ${ }^{\dagger}$ MD, \\ and Kyle R. Duchman, ${ }^{\dagger} \mathrm{MD}$ \\ Investigation performed at the University of lowa, lowa City, lowa, USA
}

\begin{abstract}
Background: Arthroscopic subtalar arthrodesis was first described over 2 decades ago and originally performed in the lateral decubitus or supine position using anterolateral and posterolateral portals situated about the fibula. More recently, several authors have advocated for prone positioning utilizing posteromedial and posterolateral portals with an optional accessory lateral portal. To date, a comparison of these techniques has been limited.
\end{abstract}

Purpose: To determine the effect of patient positioning and portal placement on complication rates after arthroscopic subtalar arthrodesis.

Study Design: Systematic review; Level of evidence, 4.

Methods: A systematic review was performed according to PRISMA (Preferred Reporting Items for Systematic Reviews and MetaAnalyses) guidelines. Patients were placed into 1 of 3 groups: the lateral group if they were positioned lateral or supine with lateralbased portals; the 2-portal prone group if they were positioned prone with posteromedial and posterolateral portals; or the 3-portal prone group if posteromedial, posterolateral, and accessory lateral portals were utilized in the prone position. Inverse varianceweighted fixed-effects models were used to evaluate pooled estimates.

Results: A total of 20 studies examining 484 feet in 468 patients with a mean follow-up of 36.1 months were included for analysis. Overall, 8 studies examined patients in the prone position with 2 posterior portals $(n=111 ; 22.9 \%), 7$ articles evaluated lateral portals $(n=182 ; 37.6 \%)$, and 5 studies examined patients in the prone position with 3 portals $(n=191 ; 39.5 \%)$. The total complication rate was similar $(P=.620)$ between the 2-portal prone (18.9\%), 3-portal prone (17.8\%), and lateral $(17.6 \%)$ groups. There was no difference observed in the rate of complications secondary to portal placement $(P \geq .334)$, rate of painful hardware $(P \geq .497)$, and rate of repeat surgery $(P \geq .304)$. The 2-portal prone group had a significantly higher rate of nonunion than the lateral group $(8.1 \%$ vs $1.1 \%$, respectively; $P=.020)$ but not the 3 -portal prone group $(5.8 \% ; P=.198)$.

Conclusion: The current study demonstrated a higher rate of nonunion following arthroscopic subtalar arthrodesis with prone patient positioning using posteromedial and posterolateral portals without an accessory lateral portal.

Keywords: subtalar joint; fusion; arthroscopic surgery; portal; complication

The subtalar joint functions primarily to provide hindfoot inversion and eversion. ${ }^{15}$ Patients with abnormalities of the subtalar joint may present with hindfoot pain, deformities, or subjective ankle instability. First-line treatment for subtalar abnormalities is often nonoperative, with surgery reserved for severe or recalcitrant cases. ${ }^{10,20,27}$ Subtalar arthrodesis is a well-described surgical option for conditions such as primary subtalar arthritis, posttraumatic arthritis, inflammatory arthritis, and congenital coalition not amenable to resection. ${ }^{5,10,11,14,29}$

The Orthopaedic Journal of Sports Medicine, 8(7), 2325967120926451 DOI: $10.1177 / 2325967120926451$

(C) The Author(s) 2020
Isolated subtalar arthrodesis was originally described using an open surgical approach, with exposure of the subtalar facets via a large lateral incision. ${ }^{10}$ The open approach to the subtalar joint has been associated with neurovascular, infectious, and bone-healing complications, with reported nonunion rates as high as $16 \% \cdot{ }^{10,20,27}$ Neurovascular structures are placed in jeopardy with the skin incision and approach, and removal of the interosseous ligaments and their corresponding vasculature may place the vascular supply to the talus at risk. ${ }^{2,18}$

Arthroscopic subtalar arthrodesis was first described in 1992, followed by a preliminary report in 1994 and a final review of the cohort in $2003 .{ }^{30}$ The procedure was originally performed with the patient in the lateral decubitus or

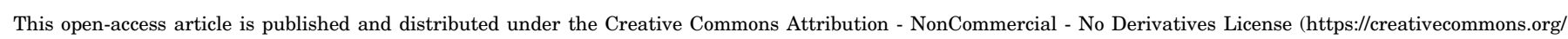

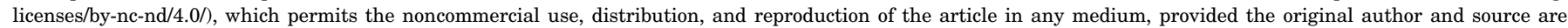

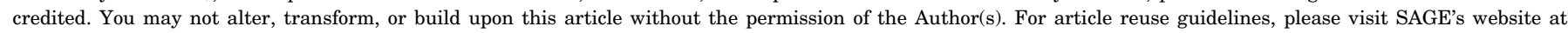
http://www.sagepub.com/journals-permissions. 
supine position using anterolateral and posterolateral portals based around the fibula with good results. ${ }^{11,13,27,35}$ More recently, several authors $\mathrm{s}^{2,3,5,21,24,26,31}$ have advocated for prone positioning utilizing posteromedial and posterolateral portals, as first described by van Dijk et al ${ }^{32}$ in 2000. Proponents of the prone position cite improved intraarticular visualization with a limited need for traction and more thorough preparation of the posterior facet for fusion. ${ }^{2}$ Additionally, the same posterior-based portals can be used to access the ankle joint to address tibiotalar abnormalities during the same procedure. ${ }^{5}$ In the prone position, a third accessory lateral portal can be utilized to assist in joint visualization and preparation while alleviating the need for traction. ${ }^{19}$

The purpose of the current study was to determine the effect of patient positioning and portal placement on complication rates after arthroscopic subtalar arthrodesis. It was hypothesized that there would be no difference in the rate of nonunion and neurovascular injuries between the different arthroscopic techniques.

\section{METHODS}

A comprehensive systematic review of the literature and subsequent meta-analysis were performed according to the PRISMA (Preferred Reporting Items for Systematic Reviews and Meta-Analyses) guidelines. Search strategies were developed by the first author (A.G.S.), with the assistance of a health sciences librarian with expertise in performing systematic reviews, using an iterative process of gathering and evaluating terms. Comprehensive strategies, including both index and keyword methods, were devised for the following databases: PubMed, Embase (Elsevier platform), and Cochrane CENTRAL. To maximize sensitivity, no pre-established database filters were used. Duplicate studies were removed using an approach to ensure accuracy and prevent accidental loss of records. This process was facilitated by citation management software, supplemented by a manual review of records. All publications were then screened by 2 independent authors (A.G.S., K.H.S.). The references and citations of relevant articles were then cross-checked for articles not discovered using the original search criteria.

All original studies with reported complication rates and a description of the operative technique for arthroscopic subtalar arthrodesis were included. Exclusion criteria consisted of meeting abstracts, technique review articles, cadaveric studies, nonisolated subtalar arthrodeses (tibiocalcaneal, double, and triple), and mixed cohort studies in which the outcomes or complication rate of arthroscopic subtalar fusion were not explicitly reported. The 2 independent reviewers collected demographic data, patient positioning, portal placement, complications, and outcomes, including time to fusion and American Orthopaedic Foot and Ankle Society (AOFAS) scores. The definition of successful subtalar arthrodesis (union) differed between studies but typically required that both specific clinical and radiographic criteria be satisfied. Patients were categorized into 1 of 3 groups: the lateral group if they were positioned in the lateral decubitus or supine position with lateral portal placement; the 2-portal prone group if they were positioned prone with posteromedial and posterolateral portals; or the 3-portal prone group if posteromedial, posterolateral, and accessory lateral portals were utilized in the prone position. The rate of complications related to portal placement (tendon or neurovascular injury), the nonunion rate, the rate of painful hardware, and any additional surgeries were also recorded. The quality of included studies was assessed by 2 reviewers (A.G.S., K.H.S.) according to the Modified Coleman Methodology Score (MCMS). ${ }^{7}$

The proportion of patients with specific complications in each group was determined and transformed using the Freeman-Tukey double arcsine method to stabilize variances. Inverse variance-weighted fixed-effects models were used to evaluate the pooled estimates using $R$ Version 3.1.1 software (metafor Meta-Analysis Package for R; R Foundation for Statistical Computing), with statistical significance defined as $P<.05$.

\section{RESULTS}

The literature search identified 300 studies, which were reviewed by the 2 independent authors (Figure 1). After a review and reference cross-examination, 20 studies ${ }^{\|}$ examining a total of 484 feet in 468 patients with a mean follow-up of 36.1 months were included for analysis (Table 1).

All selected studies were identified using the literature search strategy, as the review of reference sections did not identify additional articles for inclusion. Overall, 8 studies $^{5,9,12,18,21,22,24,31}$ examined prone patients with 2 posterior portals $(\mathrm{n}=111 ; 22.9 \%), 7$ articles ${ }^{4,11,13,16,27,30,35}$ evaluated lateral portals in the supine or lateral position $(\mathrm{n}=182 ; 37.6 \%)$, and 5 studies ${ }^{2,3,6,26,34}$ examined patients in the prone position with 3 portals $(\mathrm{n}=191 ; 39.5 \%)$. The mean MCMS of included studies was found to be 38.4

"References 2-6, 9, 11-13, 16, 18, 21, 22, 24, 26, 27, 30, 31, 34, 35.

*Address correspondence to Alan G. Shamrock, MD, Department of Orthopedics and Rehabilitation, University of lowa Hospitals and Clinics, 200 Hawkins Drive, lowa City, IA 52242, USA (email: alan-shamrock@uiowa.edu) (Twitter: @ashamrock15).

${ }^{\dagger}$ Department of Orthopedics and Rehabilitation, University of lowa Hospitals and Clinics, lowa City, lowa, USA.

${ }^{\ddagger}$ Department of Orthopaedic Surgery, Duke University, Durham, North Carolina, USA.

${ }^{\S}$ College of Osteopathic Medicine, Liberty University, Lynchburg, Virginia, USA.

Final revision submitted February 4, 2020; accepted February 19, 2020.

One or more of the authors has declared the following potential conflict of interest or source of funding: A.A. has received royalties, speaking fees, and consulting fees from Arthrex. K.R.D. has received a grant from DJO, educational support from Smith \& Nephew (provided to the Duke University Medical Center) and Arthrex, and hospitality payments from Stryker. AOSSM checks author disclosures against the Open Payments Database (OPD). AOSSM has not conducted an independent investigation on the OPD and disclaims any liability or responsibility relating thereto. 


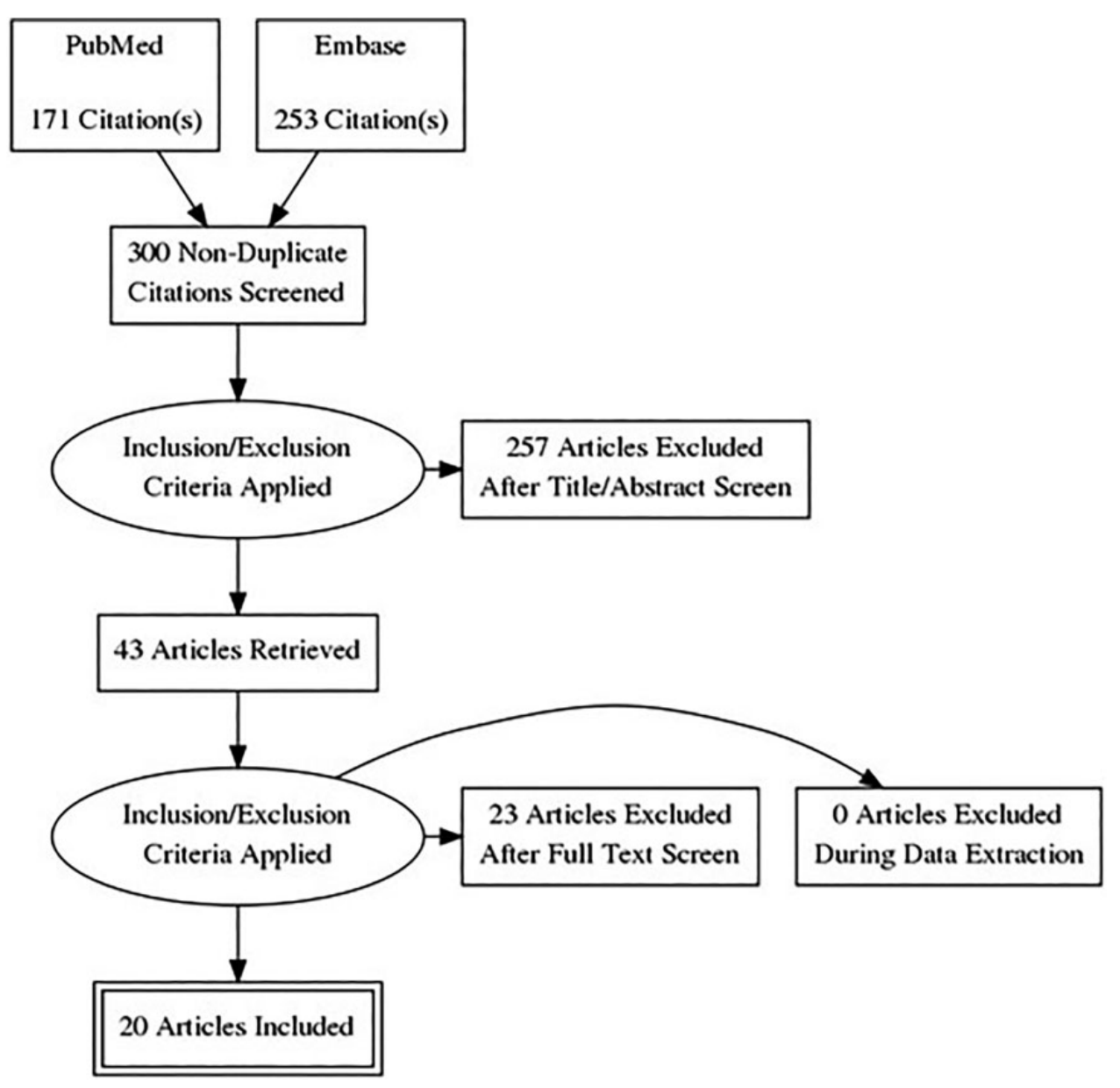

Figure 1. PRISMA (Preferred Reporting Items for Systematic Meta-Analyses) flowchart detailing the search strategy and review process.

(range, 10-63) (Table 1). Pre- and postoperative AOFAS scores were reported by 11 studies ${ }^{\top}$ (55.0\%), while time to union or the fusion rate was detailed in all but 1 study ${ }^{31}$ (95.0\%). Overall, the mean AOFAS score improved from 46.3 to 81.6 after surgery among reporting studies. Subtalar fusion was seen in $95.8 \%$ of cases at a mean of 10.9 weeks postoperatively. Although all studies utilized screw fixation, the type of screw was variable between and occasionally within studies. Typically, included studies used 1 or 2 cannulated screws $(6.5-8.0 \mathrm{~mm})$ with or without bone graft augmentation. The total complication rate was similar $(P=$ $.620)$ between the lateral $(17.6 \%), 2$-portal prone $(18.9 \%)$, and 3-portal prone (17.8\%) groups (Tables 2-4).

There was no difference observed in the rate of complications secondary to portal placement $(P \geq .334)$, rate of painful hardware $(P \geq .497)$, mean MCMS score $(P \geq .132)$, and rate of repeat surgery $(P \geq .304)$ between the 3 groups (Tables 2-5).

The 2-portal prone group had 9 cases of nonunion $(8.1 \%$ ), which were significantly more than the 2 cases of nonunion

IReferences 2, 4, 9, 11-13, 18, 21, 24, 31, 34.
(1.1\%) found in the lateral group $(P=.020)$ (Table 5). The nonunion rate of the 3 -portal prone group $(\mathrm{n}=11 ; 5.8 \%)$ was similar to that of the 2 -portal prone $(P=.198)$ and lateral $(P=.209)$ groups.

\section{DISCUSSION}

The current study demonstrated no difference in the total complication rate, rate of complications secondary to portal placement, rate of painful hardware, and rate of repeat surgery between the 3 study groups. There was a higher rate of nonunion in patients positioned prone using only posteromedial and posterolateral portals without an accessory lateral portal compared with the lateral group but not the 3-portal prone group, rendering our initial hypothesis incorrect. Furthermore, AOFAS scores improved postoperatively, with excellent reported fusion rates in the entire cohort.

Multiple studies have previously compared arthroscopic to open subtalar arthrodesis and demonstrated similar fusion rates, lower morbidity, and a high level of patient satisfaction with the arthroscopic procedure. ${ }^{26,27}$ However, until now, little work has been done comparing 
TABLE 1

Demographic Data, AOFAS Scores, Time to Union, Fusion Rates, and MCMS Scores ${ }^{a}$

\begin{tabular}{|c|c|c|c|c|c|c|c|c|c|c|}
\hline Lead Author (Year) & Group & $\begin{array}{c}\text { No. of } \\
\text { Cases/ } \\
\text { Patients }\end{array}$ & $\begin{array}{c}\text { No. of Male } \\
\text { Patients }\end{array}$ & $\begin{array}{c}\text { Mean } \\
\text { Age, } \\
\text { y }\end{array}$ & $\begin{array}{c}\text { Mean } \\
\text { Follow-up, } \\
\text { mo }\end{array}$ & $\begin{array}{c}\text { Preoperative } \\
\text { AOFAS } \\
\text { Score }\end{array}$ & $\begin{array}{c}\text { Postoperative } \\
\text { AOFAS } \\
\text { Score }\end{array}$ & $\begin{array}{l}\text { Time to } \\
\text { Union, wk }\end{array}$ & $\begin{array}{c}\text { Fusion } \\
\text { Rate, } \\
\%\end{array}$ & $\begin{array}{c}\text { MCMS } \\
\text { Score }\end{array}$ \\
\hline Boack $^{4}(2005)$ & Lateral & $22 / 20$ & 13 & 42 & 39 & 38 & 81 & 6 & 100 & 48 \\
\hline El Shazly ${ }^{11}(2009)$ & Lateral & $9 / 9$ & 7 & 42.11 & 28.4 & 38 & 74 & 11.4 & 100 & 49 \\
\hline Glanzmann $^{13}(2007)$ & Lateral & $41 / 37$ & 33 & 42 & 55 & 53 & 84 & 11 & 100 & 63 \\
\hline $\operatorname{Jerosch}^{16}(1998)$ & Lateral & $3 / 3$ & NR & NR & NR & NR & NR & NR & 100 & 10 \\
\hline Scranton $^{27}$ (1999) & Lateral & $5 / 5$ & NR & NR & $\mathrm{NR}$ & NR & NR & NR & 100 & 23 \\
\hline Tasto $^{30}(2006)$ & Lateral & $25 / 25$ & NR & NR & 22 & NR & NR & 8.9 & 100 & 33 \\
\hline Walter $^{35}(2018)$ & Lateral & $77 / 74$ & 30 & NR & NR & NR & $\mathrm{NR}$ & 15.3 & 97.4 & 49 \\
\hline $\begin{array}{l}\text { Devos Bevernage } \\
\quad(2015)\end{array}$ & 2 -portal prone & $41 / 41$ & 25 & NR & 22 & 49 & 81 & 6.7 & 95.1 & 36 \\
\hline Carro $^{5}(2007)$ & 2-portal prone & $4 / 4$ & 3 & 53 & NR & NR & NR & 8 & 100 & 25 \\
\hline Faubel $^{12}(2016)$ & 2-portal prone & $11 / 11$ & 7 & 51 & NR & 42 & 85 & 14 & 72.7 & 17 \\
\hline $\mathrm{Lee}^{18}(2010)$ & 2-portal prone & $16 / 16$ & 16 & 44 & 30 & 35 & 84 & 11 & 93.8 & 44 \\
\hline Martin Oliva $^{21}(2017)$ & 2-portal prone & $19 / 19$ & 12 & 50.9 & 42.9 & 42.4 & 80.2 & 9.8 & 94.7 & 54 \\
\hline Michels $^{22}(2011)$ & 2-portal prone & $1 / 1$ & 1 & 56 & 12 & NR & NR & 12 & 100 & 21 \\
\hline Narita $^{24}(2012)$ & 2 -portal prone & $8 / 8$ & NR & 51.5 & 26.6 & 32 & 75 & 8 & 100 & 35 \\
\hline Thaunat $^{31}(2012)$ & 2-portal prone & $11 / 10$ & NR & 52.9 & 34.2 & 51.4 & 75.6 & NR & NR & 41 \\
\hline Amendola $^{2}(2007)$ & 3-portal prone & $11 / 10$ & 5 & 41 & 34 & 36 & 86 & NR & 90.9 & 49 \\
\hline Beimers $^{3}(2009)$ & 3 -portal prone & $3 / 3$ & 0 & NR & $24-28^{b}$ & NR & NR & 6 & 100 & 35 \\
\hline Carro $^{6}(2011)$ & 3-portal prone & $43 / 43$ & 38 & 43 & 26 & NR & NR & 10 & 93 & 33 \\
\hline Rungprai $^{26}(2016)$ & 3 -portal prone & $69 / 64$ & 27 & 48.2 & 21.7 & NR & NR & 11.6 & 94.2 & 52 \\
\hline Vila-Rico $^{34}(2017)$ & 3 -portal prone & $65 / 65$ & 38 & 50 & 57.5 & 51.5 & 81.9 & 11.2 & 95.4 & 51 \\
\hline
\end{tabular}

${ }^{a}$ AOFAS, American Orthopaedic Foot and Ankle Society; MCMS, Modified Coleman Methodology Score; NR, not recorded.

${ }^{b}$ Value is shown as range.

TABLE 2

Complications of Lateral Group ${ }^{a}$

\begin{tabular}{|c|c|c|c|c|c|c|}
\hline Lead Author (Year) & $\begin{array}{c}\text { Portal } \\
\text { Complication, } \\
\mathrm{n}\end{array}$ & $\begin{array}{c}\text { Symptomatic } \\
\text { Hardware, } \\
\text { n }\end{array}$ & $\underset{\mathrm{n}}{\text { Nonunion, }}$ & $\begin{array}{c}\text { Repeat } \\
\text { Surgery, } \\
\text { n }\end{array}$ & $\begin{array}{c}\text { Total } \\
\text { Complications, } \\
\mathrm{n}\end{array}$ & Complication Details \\
\hline $\operatorname{Boack}^{4}(2005)$ & 0 & 0 & 0 & 0 & 0 & NA \\
\hline El Shazly ${ }^{11}(2009)$ & 1 & 0 & 0 & 0 & 1 & 1 painful neuroma at site of anterolateral portal \\
\hline Glanzmann $^{13}(2007)$ & 1 & 10 & 0 & 10 & 14 & $\begin{array}{l}3 \text { persistent ankle pain, } 1 \text { peroneal tendinitis, } 10 \\
\text { painful hardware requiring removal }\end{array}$ \\
\hline $\operatorname{Jerosch}^{16}(1998)$ & 0 & 0 & 0 & 0 & 1 & $\begin{array}{l}1 \text { algodystrophy (leading to prolonged } \\
\text { rehabilitation but final outcome excellent) }\end{array}$ \\
\hline Scranton $^{27}(1999)$ & 0 & 1 & 0 & 1 & 1 & 1 painful hardware requiring removal \\
\hline Tasto $^{30}(2006)$ & 0 & 1 & 0 & 1 & 1 & 1 painful hardware requiring removal \\
\hline Walter $^{35}(2018)$ & 2 & 7 & 2 & 10 & 14 & $\begin{array}{l}7 \text { painful hardware requiring removal, } 2 \text { open } \\
\text { revision arthrodesis with bone grafting for } \\
\text { painful aseptic nonunion, } 1 \text { superficial portal } \\
\text { site infection, } 1 \text { sural neuropathic pain, } 1 \\
\text { complex regional pain syndrome, } 1 \text { flexor } \\
\text { hallucis longus tendon rupture, } 1 \text { deep vein } \\
\text { thrombosis }\end{array}$ \\
\hline Total, n (\%) & $4(2.2)$ & $19(10.4)$ & $2(1.1)$ & $22(12.1)$ & $32(17.6)$ & \\
\hline
\end{tabular}

${ }^{a} \mathrm{NA}$, not applicable.

arthroscopic techniques, as the majority of the literature regarding arthroscopic subtalar arthrodesis consists of small case series.

Patient-reported outcome scores after arthroscopic subtalar arthrodesis have been consistently reported as excellent in the literature, regardless of patient positioning or portal placement. ${ }^{2,4,11,13,18,21,34}$ Amendola et $\mathrm{al}^{2}$ reported an improvement in the mean AOFAS score from 36 to 86 in a series of 11 arthroscopic subtalar fusion cases in the prone position with 2 posterior portals and a third 
TABLE 3

Complications of 2-Portal Prone Group ${ }^{a}$

\begin{tabular}{|c|c|c|c|c|c|c|}
\hline Lead Author (Year) & $\begin{array}{l}\text { Portal } \\
\text { Complication, } \\
\mathrm{n}\end{array}$ & $\begin{array}{l}\text { Symptomatic } \\
\text { Hardware, } \\
\text { n }\end{array}$ & $\underset{n}{\text { Nonunion, }}$ & $\begin{array}{l}\text { Repeat } \\
\text { Surgery, } \\
\mathrm{n}\end{array}$ & $\begin{array}{l}\text { Total } \\
\text { Complications, } \\
\mathrm{n}\end{array}$ & Complication Details \\
\hline Devos Bevernage $^{9}$ (2015) & 0 & 0 & 2 & 3 & 5 & $\begin{array}{l}2 \text { nonunion requiring open surgery with } \\
\text { bone grafting, } 3 \text { lateral submalleolar } \\
\text { impingement ( } 1 \text { requiring resection of } \\
\text { lateral calcaneal edge) }\end{array}$ \\
\hline Carro $^{5}(2007)$ & 0 & 0 & 0 & 0 & 0 & NA \\
\hline Faubel $^{12}(2016)$ & 0 & 3 & 3 & 6 & 6 & $\begin{array}{l}3 \text { nonunion requiring revision open surgery } \\
\text { with iliac crest bone graft, } 3 \text { painful } \\
\text { hardware requiring removal }\end{array}$ \\
\hline $\mathrm{Lee}^{18}(2010)$ & 0 & 0 & 1 & 1 & 1 & $\begin{array}{l}1 \text { deep infection leading to nonunion } \\
\text { requiring revision with removal of } \\
\text { hardware }\end{array}$ \\
\hline Martin Oliva ${ }^{21}(2017)$ & 1 & 2 & 1 & 3 & 4 & $\begin{array}{l}2 \text { painful hardware requiring removal, } \\
1 \text { neurapraxia, } 1 \text { nonunion requiring open } \\
\text { revision surgery with bone grafting }\end{array}$ \\
\hline Michels $^{22}(2011)$ & 0 & 0 & 0 & 0 & 0 & NA \\
\hline Narita $^{24}(2012)$ & 0 & 0 & 0 & 0 & 0 & $\mathrm{NA}$ \\
\hline Thaunat $^{31}(2012)$ & 1 & 1 & 2 & 4 & 5 & $\begin{array}{l}1 \text { sural nerve injury requiring neurolysis, } \\
1 \text { delayed union requiring revision, } \\
2 \text { nonunion, } 1 \text { painful hardware requiring } \\
\text { removal }\end{array}$ \\
\hline Total, n (\%) & $2(1.8)$ & $6(5.4)$ & $9(8.1)$ & $17(15.3)$ & $21(18.9)$ & \\
\hline
\end{tabular}

${ }^{a} \mathrm{NA}$, not applicable.

TABLE 4

Complications of 3-Portal Prone Group ${ }^{a}$

\begin{tabular}{|c|c|c|c|c|c|c|}
\hline Lead Author (Year) & $\begin{array}{l}\text { Portal } \\
\text { Complication, } \\
\mathrm{n}\end{array}$ & $\begin{array}{l}\text { Symptomatic } \\
\text { Hardware, } \\
\text { n }\end{array}$ & $\begin{array}{c}\text { Nonunion, } \\
\mathrm{n}\end{array}$ & $\begin{array}{l}\text { Repeat } \\
\text { Surgery, } \\
\text { n }\end{array}$ & $\begin{array}{l}\text { Total } \\
\text { Complications, } \\
\mathrm{n}\end{array}$ & Complication Details \\
\hline Amendola $^{2}$ (2007) & 0 & 1 & 1 & 2 & 2 & $\begin{array}{c}1 \text { nonunion requiring revision surgery, } 1 \\
\text { painful hardware requiring removal }\end{array}$ \\
\hline Beimers $^{3}(2009)$ & 0 & 0 & 0 & 0 & 0 & NA \\
\hline Carro $^{6}(2011)$ & 0 & 0 & 3 & 2 & 3 & $\begin{array}{l}3 \text { nonunion ( } 1 \text { requiring talocalcaneal } \\
\text { fusion with intramedullary rod and } 1 \\
\text { requiring open revision arthrodesis with } \\
\text { iliac crest bone graft) }\end{array}$ \\
\hline Rungprai $^{26}(2016)$ & 4 & 9 & 4 & 13 & 20 & $\begin{array}{l}4 \text { nonunion requiring revision surgery, } 9 \\
\text { painful hardware requiring removal, } 4 \\
\text { sural nerve dysesthesia, } 1 \text { complex } \\
\text { regional pain syndrome, } 2 \text { painful scar }\end{array}$ \\
\hline Vila-Rico ${ }^{34}(2017)$ & 0 & 5 & 3 & 8 & 9 & $\begin{array}{l}1 \text { superficial portal infection, } 5 \text { painful } \\
\text { hardware requiring removal, } 3 \text { nonunion } \\
\text { ( } 2 \text { requiring open revision and } 1 \\
\text { requiring arthroscopic revision) }\end{array}$ \\
\hline Total, n (\%) & $4(2.1)$ & $15(7.9)$ & $11(5.8)$ & $25(13.1)$ & $34(17.8)$ & \\
\hline
\end{tabular}

${ }^{a} \mathrm{NA}$, not applicable.

accessory lateral portal. In a case series of 22 arthroscopic subtalar fusion procedures using lateral-based portals, Boack et $\mathrm{al}^{4}$ reported an improvement in the AOFAS score from 38 to 81 . Martin Oliva et al $^{21}$ examined 19 patients undergoing arthroscopic subtalar fusion in the prone position using 2 portals and found that the AOFAS score improved from 42.4 to 80.2 . Of the 20 articles that met the inclusion criteria of our study, only 11 (55.0\%) reported both preoperative and postoperative AOFAS scores. Among these patients, the mean AOFAS score improved from 46.3 to 81.6 after surgery. This overall mean improvement is consistent with prior studies 
TABLE 5

$P$ Values Comparing Outcomes Between Study Groups ${ }^{a}$

\begin{tabular}{|c|c|c|c|c|c|}
\hline & Portal Complication & Symptomatic Hardware & Nonunion & Repeat Surgery & MCMS \\
\hline Lateral vs 2 -portal prone & .509 & .748 & $.020^{b}$ & .304 & .542 \\
\hline Lateral vs 3-portal prone & .702 & .497 & .209 & .917 & .571 \\
\hline 2-portal prone vs 3-portal prone & .334 & .733 & .198 & .354 & .132 \\
\hline
\end{tabular}

${ }^{a}$ MCMS, Modified Coleman Methodology Score.

${ }^{b}$ Statistically significant $(P<.05)$.

demonstrating mean improvements in the AOFAS score postoperatively from 31 to $50 .^{1,2,18}$ Unfortunately, the limited number of reporting studies precluded the possibility of subgroup analyses of AOFAS scores based on patient positioning or portal placement, which remains a topic for further study.

Previous literature comparing open with arthroscopic subtalar arthrodesis has demonstrated decreased morbidity with the arthroscopic technique. ${ }^{26,27}$ Rungprai et al $^{26}$ retrospectively reviewed 60 open and 69 arthroscopic subtalar fusion cases and found that sural nerve injuries and painful surgical scars were more frequent in the open group, while hardware-related symptoms were more frequent in the arthroscopic group. Another study demonstrated that the arthroscopic technique was associated with a decreased length of hospital stay. ${ }^{27}$ Literature comparing complication rates of the arthroscopic technique based on portal placement and patient positioning is lacking. In our study, no difference was found between the 3 study groups for total complication rate, rate of complications secondary to portal placement (tendon or neurovascular injuries), rate of painful hardware, and rate of repeat surgery. Proponents of the 2-portal prone technique consistently cite the relative safety of the posteromedial and posterolateral portals with respect to sural nerve injuries compared with lateral portals based around the fibula, although this notion is not supported by our findings. ${ }^{32}$

Of the 20 studies included in our systematic review, all but 1 recorded fusion rates and time to fusion. Successful fusion was consistently defined clinically as a pain-free subtalar joint and radiographically defined as osseous bridging visualized on either plain radiographs or computed tomography scans. Using these definitions, subtalar fusion was reported in $95.8 \%$ of cases at a mean of 10.9 weeks postoperatively. Previous studies have noted fusion rates from $91 \%$ to $100 \%$ with a time to union from 7 to 11 weeks. ${ }^{1,2,18}$ The included studies described 22 total nonunion cases, half of which were in the 3-portal prone group. There was a statistically significant difference in the nonunion rate when the 2-portal prone group was compared with the lateral group but not the 3-portal prone group. The exact cause of this relationship is unclear. However, we theorize that the strict use of posterior portals precludes full preparation of the convex posterior facet, particularly when working anteriorly along the posterior facet using posterior-based portals. The third accessory lateral portal allows the introduction of a trocar for joint distraction to provide additional joint visualization and preparation.
This hypothesis is further supported by a cadaveric study demonstrating that the greatest surface area of the posterior facet is accessed with 2 posterior portals and a third lateral portal. ${ }^{25}$ The current study suggests that these differences are clinically relevant when considering the reported rates of nonunion.

\section{Limitations}

The current study has several limitations. The design of a systematic review is limiting and relies on other authors to report data accurately. The study is predisposed to publication bias. Additionally, the method of fixation varied between and within studies. Although previous work comparing 1 or 2 screw fixation techniques has produced differing results, a few studies unfortunately did not report their surgical technique, which precluded subgroup analyses. ${ }^{8,33}$ The method of radiographic evaluation differed widely between plain radiography, computed tomography, and a combination of the 2 modalities. The use of a bone graft for fusion augmentation was also heterogeneous in the included studies and may have affected nonunion rates and time to union. ${ }^{17,23,28}$ Furthermore, the definition of time to union was heterogeneous among the included studies. Additionally, the heterogeneity of the screw number and type between and within the included studies precluded further analyses regarding the appropriate number and type of screws for fixation. A few studies used both clinical and radiographic criteria for fusion, while others determined successful arthrodesis as when the patient was pain-free regardless of the radiographic appearance. The current study is also unable to account for surgeon experience, operative volume, and comfort level with the procedure. Operative characteristics of the arthroscopic procedures such as operative times, blood loss, and airway complications related to prone positioning were not assessed.

\section{CONCLUSION}

Arthroscopic subtalar arthrodesis was an effective treatment option for subtalar joint abnormalities with improved postoperative AOFAS scores, regardless of patient positioning or portal placement. A higher rate of nonunion was identified when the patient was positioned prone and posteromedial and posterolateral portals without an accessory lateral portal were utilized. While this finding has not been described previously, it may relate to incomplete 
visualization and/or preparation of the entire posterior facet. Based on these findings, further large-scale prospective studies are warranted.

\section{REFERENCES}

1. Albert A, Deleu PA, Leemrijse T, Maldague P, Devos Bevernage B. Posterior arthroscopic subtalar arthrodesis: ten cases at one-year follow-up. Orthop Traumatol Surg Res. 2011;97(4):401-405.

2. Amendola A, Lee KB, Saltzman CL, Suh JS. Technique and early experience with posterior arthroscopic subtalar arthrodesis. Foot Ankle Int. 2007;28(3):298-302.

3. Beimers L, de Leeuw PA, van Dijk CN. A 3-portal approach for arthroscopic subtalar arthrodesis. Knee Surg Sports Traumatol Arthrosc. 2009;17(7):830-834.

4. Boack DH, Manegold S, Friedebold A, Haas NP. [Arthroscopic in situ arthrodesis of the subtalar joint]. Orthopade. 2005;34(12): 1245-1254.

5. Carro LP, Golano P, Vega J. Arthroscopic subtalar arthrodesis: the posterior approach in the prone position. Arthroscopy. 2007;23(4): 445.e1-4.

6. Carro LP, Golano P, Escajadillo NF, Vega J, Vallejo MR, Rubin CG. Arthroscopic subtalar arthrodesis: the posterior approach in the prone position. Tech Foot Ankle Surg. 2011;10(3):127-132.

7. Coleman BD, Khan KM, Maffulli N, Cook JL, Wark JD. Studies of surgical outcome after patellar tendinopathy: clinical significance of methodological deficiencies and guidelines for future studies. Victorian Institute of Sport Tendon Study Group. Scand J Med Sci Sports. 2000;10(1):2-11.

8. DeCarbo WT, Berlet GC, Hyer CF, Smith WB. Single-screw fixation for subtalar joint fusion does not increase nonunion rate. Foot Ankle Spec. 2010;3(4):164-166.

9. Devos Bevernage B, Goubau L, Deleu PA, Gombault V, Maldague P, Leemrijse T. Posterior arthroscopic subtalar arthrodesis. JBJS Essent Surg Tech. 2015;5(4):e27.

10. Easley ME, Trnka HJ, Schon LC, Myerson MS. Isolated subtalar arthrodesis. J Bone Joint Surg Am. 2000;82(5):613-624.

11. El Shazly O, Nassar W, El Badrawy A. Arthroscopic subtalar fusion for post-traumatic subtalar arthritis. Arthroscopy. 2009;25(7): 783-787.

12. Faubel EN, Carsi VV, Gonzalez MS. Arthroscopic subtalar arthrodesis. Revista del Pie y Tobillo. 2016;30(2):71-75.

13. Glanzmann MC, Sanhueza-Hernandez R. Arthroscopic subtalar arthrodesis for symptomatic osteoarthritis of the hindfoot: a prospective study of 41 cases. Foot Ankle Int. 2007;28(1):2-7.

14. Huang PJ, Fu YC, Cheng YM, Lin SY. Subtalar arthrodesis for late sequelae of calcaneal fractures: fusion in situ versus fusion with sliding corrective osteotomy. Foot Ankle Int. 1999;20(3):166-170.

15. Jastifer JR, Gustafson PA. The subtalar joint: biomechanics and functional representations in the literature. Foot (Edinb). 2014;24(4): 203-209.

16. Jerosch J. Subtalar arthroscopy: indications and surgical technique. Knee Surg Sports Traumatol Arthrosc. 1998;6(2):122-128.

17. Lareau CR, Deren ME, Fantry A, Donahue RM, DiGiovanni CW. Does autogenous bone graft work? A logistic regression analysis of data from 159 papers in the foot and ankle literature. Foot Ankle Surg. 2015;21(3):150-159.

18. Lee KB, Park CH, Seon JK, Kim MS. Arthroscopic subtalar arthrodesis using a posterior 2-portal approach in the prone position. Arthroscopy. 2010;26(2):230-238.

19. Lee KB, Saltzman CL, Suh JS, Wasserman L, Amendola A. A posterior 3-portal arthroscopic approach for isolated subtalar arthrodesis. Arthroscopy. 2008;24(11):1306-1310.

20. Mann RA, Beaman DN, Horton GA. Isolated subtalar arthrodesis. Foot Ankle Int. 1998;19(8):511-519.

21. Martin Oliva X, Falcao P, Fernandes Cerqueira R, Rodrigues-Pinto R. Posterior arthroscopic subtalar arthrodesis: clinical and radiologic review of 19 cases. J Foot Ankle Surg. 2017;56(3):543-546.

22. Michels F, Stockmans F, Guillo S, Van Der Bauwhede J, Oosterlinck D. Arthroscopic subtalar arthrodesis after a calcaneus fracture covered with a forearm flap. Minim Invasive Surg. 2011;2011:930902.

23. Michelson JD, Curl LA. Use of demineralized bone matrix in hindfoot arthrodesis. Clin Orthop Relat Res. 1996;325:203-208.

24. Narita N, Takao M, Innami K, Kato H, Matsushita T. Minimally invasive subtalar arthrodesis with iliac crest autograft through posterior arthroscopic portals: a technical note. Foot Ankle Int. 2012; 33(9):803-805.

25. Phisitkul P, Tochigi Y, Saltzman CL, Amendola A. Arthroscopic visualization of the posterior subtalar joint in the prone position: a cadaver study. Arthroscopy. 2006;22(5):511-515.

26. Rungprai C, Phisitkul P, Femino JE, Martin KD, Saltzman CL, Amendola $A$. Outcomes and complications after open versus posterior arthroscopic subtalar arthrodesis in 121 patients. J Bone Joint Surg Am. 2016;98(8):636-646.

27. Scranton PE Jr. Comparison of open isolated subtalar arthrodesis with autogenous bone graft versus outpatient arthroscopic subtalar arthrodesis using injectable bone morphogenic protein-enhanced graft. Foot Ankle Int. 1999;20(3):162-165.

28. Shah A, Naranje S, Araoye I, Elattar O, Godoy-Santos AL, Cesar CN. Role of bone grafts and bone graft substitutes in isolated subtalar joint arthrodesis. Acta Ortop Bras. 2017;25(5):183-187.

29. Swiontkowski MF, Scranton PE, Hansen S. Tarsal coalitions: longterm results of surgical treatment. J Pediatr Orthop. 1983;3(3): 287-292.

30. Tasto JP. Arthroscopy of the subtalar joint and arthroscopic subtalar arthrodesis. Instr Course Lect. 2006;55:555-564.

31. Thaunat M, Bajard X, Boisrenoult P, Beaufils P, Oger P. Computer tomography assessment of the fusion rate after posterior arthroscopic subtalar arthrodesis. Int Orthop. 2012;36(5):1005-1010.

32. van Dijk CN, Scholten PE, Krips R. A 2-portal endoscopic approach for diagnosis and treatment of posterior ankle pathology. Arthroscopy. 2000;16(8):871-876.

33. Vila-Rico J, Bravo-Gimenez B, Jimenez-Diaz V, Mellado-Romero MA, Ojeda-Thies C. Arthroscopic subtalar arthrodesis: does the type of fixation modify outcomes? J Foot Ankle Surg. 2018;57(4):726-731.

34. Vila-Rico J, Mellado-Romero MA, Bravo-Gimenez B, Jimenez-Diaz V, Ojeda-Thies C. Subtalar arthroscopic arthrodesis: technique and outcomes. Foot Ankle Surg. 2017;23(1):9-15.

35. Walter RP, Walker RW, Butler M, Parsons S. Arthroscopic subtalar arthrodesis through the sinus tarsi portal approach: a series of 77 cases. Foot Ankle Surg. 2018;24(5):417-422. 